\title{
Hemoglobin Q-Iran detected in family members from Northern Iran: a case report
}

\author{
Mohammad Khorshidi ${ }^{1}$, Payam Roshan ${ }^{2}$, Nooshin Bayat ${ }^{3}$, Mohammad Reza Mahdavi ${ }^{1,2}$ and Hossein Najmabadi ${ }^{3^{*}}$
}

\begin{abstract}
Introduction: Hemoglobin Q-Iran ( $\alpha 75 \mathrm{Asp} \rightarrow \mathrm{His}$ ) is an important member of the hemoglobin Q family, molecularly characterized by the replacement of aspartic acid by histidine. The first report of hemoglobin Q-Iran and the nomenclature of this hemoglobinopathy dates back to 1970. Iran is known as a country with a high prevalence of $\alpha$ - and $\beta$-thalassemia and different types of hemoglobinopathy. Many of these variants are yet to be identified as the practice of molecular laboratory techniques is limited in this part of the world. Applying such molecular methods, we report the first hemoglobin Q-Iran cases in Northern Iran.
\end{abstract}

Case presentation: An unusual band was detected in an isoelectric focusing test and cellulose acetate electrophoresis of a sample from a 22-year-old Iranian man from Mazandaran Province. Capillary zone electrophoresis analysis identified this band as hemoglobin Q. A similar band was also detected in his mother's electrophoresis (38 years, Iranian ethnicity). The cases underwent molecular investigation and the presence of a hemoglobin Q-Iran mutation was confirmed by the amplification refractory mutation system polymerase chain reaction method. Direct conventional sequencing revealed a single guanine to cytosine missense mutation (c.226G $>C_{i}$ GAC > CAC) at codon 75 in the $\alpha$-globin gene in both cases.

Conclusion: The wide spectrum and high frequency of nondeletional $\alpha$-globin mutations in Mazandaran Province is remarkable and seem to differ considerably from what has been found in Mediterranean populations. This short communication reports the first cases of patients with hemoglobin $Q$ found in that region.

\section{Introduction}

Hemoglobin $(\mathrm{Hb}) \mathrm{Q}$ is a single nucleotide polymorphism occurring in the $\mathrm{Hb} \alpha-2$ chain. $\mathrm{Hb} \mathrm{Q}$ variants are recognized by a slow-moving band migrating at a similar position to $\mathrm{Hb} \mathrm{S}$ on alkaline $\mathrm{pH}$ electrophoresis. This $\mathrm{Hb} \mathrm{Q}$ variant has normal solubility [1].

A number of important members of the $\mathrm{Hb} \mathrm{Q}$ family share a certain molecular feature-the replacement of aspartic acid (Asp) by histidine (His) at different positions in the amino acid chain. These include $\mathrm{Hb}$ QThailand ( $\alpha 74$ Asp $\rightarrow$ His), Q-India ( $\alpha 64$ Asp $\rightarrow$ His) and Q-Iran ( $\alpha 75$ Asp $\rightarrow$ His). The association of Hb Q-Thailand with $\alpha$-thalassemia is frequently reported and the majority of patients show moderate red cell microcytosis [2]. In contrast, there are few reports of any affiliation

\footnotetext{
* Correspondence: hnajm12@yahoo.com

${ }^{3}$ Kariminejad-Najmabadi Pathology \& Genetics Center, 2 Medical Building, 4th Street, Hassan Seyf Street, Shahrak Gharb, Tehran, PO Box: 14665/154, Iran

Full list of author information is available at the end of the article
}

of $\mathrm{Hb} \mathrm{Q}$-India and $\mathrm{Hb} \mathrm{Q}$-Iran with other $\mathrm{Hb}$ disorders and deletions [3].

Computerized simulation of secondary and tertiary protein structures of these $\mathrm{Hb}$ molecules by standard bioinformatic methods suggest that $\mathrm{Hb} \mathrm{Q}$-Iran and $\mathrm{Hb}$ Q-Thailand have one and two extra helices respectively, whilst $\mathrm{Hb} \mathrm{Q}$-India has a protein structure similar to the normal $\mathrm{Hb}$ molecule [4]. In the heterozygous state, patients with $\mathrm{Hb} \mathrm{Q}$-India or $\mathrm{Hb} \mathrm{Q}$-Iran do not have the thalassemia phenotype or any distinctive clinical manifestation. Furthermore, these $\mathrm{Hb}$ abnormalities do not affect hematologic features. The replacement of aspartic acid with histidine is on the surface of the protein structure and does not affect the protein interchain contacts and electrical charges of the molecule, and therefore does not cause any changes in hematologic parameters and indices [5]. Interestingly, in a unique report of a homozygous patient with $\mathrm{Hb}$ Q-Iran, no clinical symptom was observed [6].

\section{() Biomed Central}


The first report of $\mathrm{Hb} \mathrm{Q}$-Iran and the nomenclature of this hemoglobinopathy dates back to 1970 and the work of Lorkin et al., introducing the substitution of aspartic acid by histidine at position $\alpha 75$ (EF4) as the responsible defect for this hemoglobinopathy [5]. In 2007, Rahimi and colleagues reported the first incidence of such a hemoglobinopathy in an Iranian individual [7].

Iran is known as a country with a high prevalence of $\alpha$ - and $\beta$-thalassemia and different types of hemoglobinopathy. Many of these variants are yet to be identified as the practice of molecular laboratory techniques is limited in this part of the world. Applying molecular methods, we here report the first cases of patients with $\mathrm{Hb}$ Q-Iran in Northern Iran.

\section{Case presentation}

A 22-year-old Iranian man originally from the northern province of Mazandaran, was admitted to Fajr Laboratory Center (Sari, Iran) for premarital thalassemia screening. All evaluated hematologic indices were in the normal range (Table 1); however, both isoelectric focusing and cellulose acetate electrophoresis techniques revealed an unusual slow moving electrophoretic band in the location of $\mathrm{Hb} \mathrm{Q}$. A hematological investigation was then performed for the whole family. His father's blood tableau and $\mathrm{Hb}$ electrophoretic pattern were completely normal. His mother was a 38-year-old of Iranian ethnicity with normal hematologic indices. Her $\mathrm{Hb}$ electrophoretic pattern contained a band suspected to be $\mathrm{Hb} \mathrm{Q}$. Further evaluation by automatic capillary zone electrophoresis (Minicap system, Sebia, France) revealed an extra peak in the graphs of our two patients, identified as $\mathrm{Hb} \mathrm{Q}$ (Table 1). Previous reports of the quantity of $\mathrm{Hb}$ Q-Iran are stated to be $17 \%$ to $19 \%$ of the total $\mathrm{Hb}$ content. In our study, we found the amount of $\mathrm{Hb}$ Q-Iran to be $19.2 \%$ in these heterozygous individuals.

Table 1 Hematologic indices and $\mathrm{Hb}$ electrophoresis of our patients.

\begin{tabular}{lrr}
\hline & Proband & Mother \\
\hline Sex & Male & Female \\
Age (years) & 22 & 38 \\
Red blood cells $\left(\times 10^{6} / \mu \mathrm{L}\right)$ & 5.69 & 4.56 \\
$\mathrm{Hb}(\mathrm{g} / \mathrm{dL})$ & 15.7 & 12.6 \\
Hematocrit (\%) & 46.9 & 37.2 \\
Mean corpuscular volume & 82.4 & 81.7 \\
MCH & 27.7 & 27.6 \\
MCH concentration (\%) & 33.6 & 33.8 \\
Hb A (\%) & 78.2 & 78.3 \\
Hb A2 (\%) & 2.1 & 2 \\
Hb A2 variant (\%) & 0.5 & 0.5 \\
Hb Q (\%) & 19.2 & 19.2 \\
\hline
\end{tabular}

$\mathrm{Hb}$ : hemoglobin; $\mathrm{MCH}$ : Mean corpuscular hemoglobin
The family was then referred to the Kariminejad-Najmabadi Pathology and Genetics Center for molecular analysis. Deoxyribonucleic acid (DNA) samples were obtained from all members of the family and analyzed for $\alpha$-globin mutations. The samples were examined by DNA analysis for the presence of the Hb Q-Iran mutation using the amplification refractory mutation system polymerase chain reaction method. Automated direct nucleotide sequencing (ABII377, Applied Biosystems, Foster City, California, USA) of the amplified $\alpha 2$ - and $\alpha 1$-globin genes was performed to characterize other nondeletional $\alpha$-thalassemia determinants. Direct conventional sequencing revealed a single guanine to cytosine missense mutation (c.226G > C; GAC >CAC) at codon 75 in the $\alpha$-globin gene in all samples except from the father (Figure 1). No other $\alpha$-globin mutation could be detected by direct nucleotide sequencing.

Despite the normal clinical features of our patients, laboratory findings led to the identification of a rare $\mathrm{Hb}$ variant, Hb Q-Iran. Hereby, we report a family in the north of Iran whose members are carriers of the $\mathrm{Hb} \mathrm{Q}$ Iran gene.

\section{Discussion}

Iran is a multiethnic country with a vast variation of thalassemia-causing mutations and there are reports of hemoglobinopathies from different regions of that country [8]. The northern (Mazandaran and Gilan) and southern (Khuzestan) provinces of Iran are the areas most prone to different $\mathrm{Hb}$ abnormalities and there have been several studies for identification of these variants in these regions [9]. Mazandaran is a province in the north of Iran, by the Caspian Sea. The wide spectrum and high frequency of nondeletional $\alpha$-globin mutations in Mazandaran Province is remarkable and seems to differ considerably from what has been found in Mediterranean populations [9].

We have previously reported of less common $\mathrm{Hb} \alpha$ chain mutations in that region, namely initiation codon mutation (ATG > AGG, $\alpha 2$ ), J-Paris-I (GCC > GAC, $\alpha 1$ ), codon 14 mutation (TGG > TAG, $\alpha 1$ ), codon 22 mutation (GGC > GGT, $\alpha 2)$, Caserta (GCG > ACG, $\alpha 2$ ), intervening sequence (IVS)-I-116 (A > G, $\alpha 2)$, IVSII-55 ( $\mathrm{T}>\mathrm{G}, \alpha 2)$, Bleuland (ACC > AAC, $\alpha 2)$, Sun Prairie (GCT > CCT, $\alpha 2)$, 3'UTR nt 46 (C > A, $\alpha 2)$ [9], J-Toronto $(\mathrm{GCC}>\mathrm{GAC}, \alpha 1)$ and Setif $(\mathrm{GAC}>\mathrm{TAC}$, $\alpha 2)$ [10]. This short communication reports the first $\mathrm{Hb}$ $\mathrm{Q}$ cases found in that region.

Besides Iran, there have been several reports of $\mathrm{Hb}-\mathrm{Q}$ from Turkey $[3,6]$. This is not the first hemoglobinopathy in common between Iranian and Turkish populations. There are several findings of different abnormal $\mathrm{Hb}$ molecules such as Hb J-Iran, Hb D-Iran, Hb Hamadan and Hb D-Punjab in people of both ethnicities [11]. 


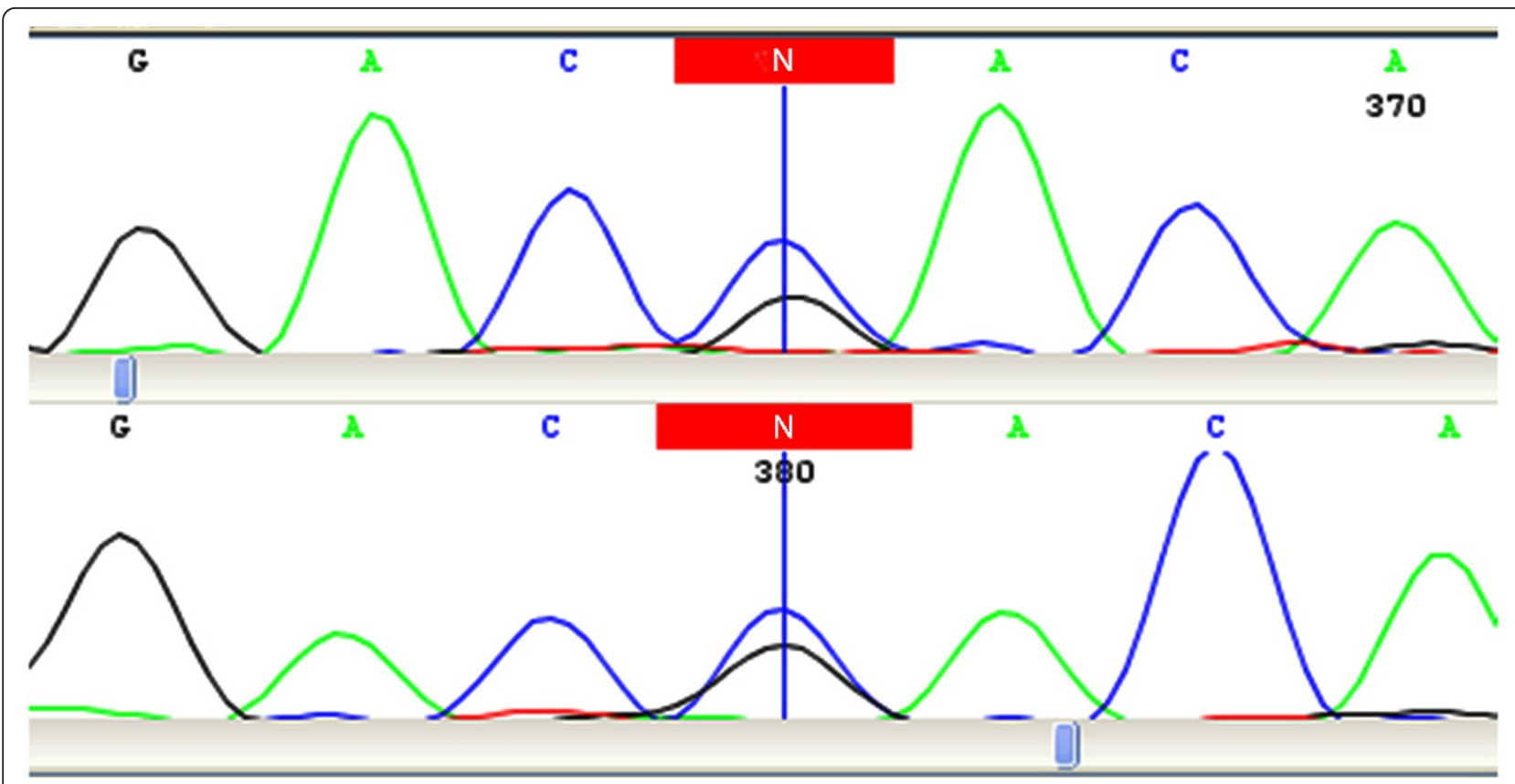

Figure 1 Deoxyribonucleic acid sequence analysis of the $\alpha 2$-globin gene. The coding exon deoxyribonucleic acid from our patient was amplified by polymerase chain reaction and sequenced. A segment of the nucleotide sequences containing the mutation is shown. The position of the single guanine to cytosine missense mutation (codon $75 \mathrm{G}>\mathrm{C}$ ) is indicated by the colored box.

These findings, along with further haplotype studies, may suggest a common ancestral origin for the people in that region and help to propose immigration patterns at the time of colonization by Aryans on the Iranian Plateau and in Middle Asia, circa 4,000 BC.

\section{Conclusion}

Different hemoglobinopathies are frequently reported from Northern Iran, but this is the first report of an $\mathrm{Hb}$ Q-Iran mutation in members of a family from that region. This report provides a substantial piece of evidence in completing the list of discovered $\mathrm{Hb}$ abnormalities on the southern shores of the Caspian Sea.

\section{Consent}

Written informed consent was obtained from the patient and his mother for publication of this case report and any accompanying images. A copy of the written consent is available for review by the Editor-in-Chief of this journal.

\section{Author details}

'Thalassemia Research Center, Mazandaran University of Medical Sciences, Sari, Iran. ${ }^{2}$ Research Department, Fajr Laboratory Center, Keshavarz Boulevard, Sari, Iran. ${ }^{3}$ Kariminejad-Najmabadi Pathology \& Genetics Center, 2 Medical Building, 4th Street, Hassan Seyf Street, Shahrak Gharb, Tehran, PO Box: 14665/154, Iran

\section{Authors' contributions}

MK performed the clinical examination of the patients and introduced the cases. PR performed the laboratory work and analysis and wrote the case reports. NB carried out the molecular laboratory work. MRM carried out the laboratory work and analysis of the data. HN performed the molecular laboratory work, wrote the molecular section and revised the case reports. Hereby all authors verify that they read and approved the final manuscript.

\section{Competing interests}

The authors declare that they have no competing interests.

Received: 22 September 2011 Accepted: 6 February 2012 Published: 6 February 2012

\section{References}

1. Rahimi Z, Rezaei M, L Nagel R, Muniz A: Molecular and hematologic analysis of hemoglobin Q-Iran and hemoglobin Setif in Iranian families. Arch Iran Med 2008, 11(4):382-386.

2. Zheng W, Liu Y, Chen D, Rong K, Ge Y, Gong C, Chen H: Complex interaction of $\mathrm{Hb} \mathrm{Q}$-Thailand and $\mathrm{Hb} \mathrm{E}$ with alpha (0)-thalassemia and hereditary persistence of fetal hemoglobin in a Chinese family. Ann Hematol 2010, 89(9):883-888.

3. Gürgey A, Ozsoylu S, Hiçsönmez G, Irken G, Altay C: Acute lymphoblastic leukemia in a child with hemoglobins S and Q-Iran. Turk J Pediatr 1990, 32(1):39-41.

4. Yadav AK: Comparative analysis of protein structure of common $\mathrm{Hb} \mathrm{Q}$ variants. Indian J Pathol Microbiol 2010, 53(4):696-698.

5. Lorkin PA, Charlesworth D, Lehmann H, Rahbar S, Tuchinda S, Eng Ll: Two haemoglobins Q, alpha-74 (EF3) and alpha-75 (EF4) aspartic acid to histidine. Br J Haematol 1970, 19(1):117-125.

6. Ozdag H, Yildiz I, Akar N: First observation of homozygote $\mathrm{Hb}$ Q-Iran (alpha 75 (EF4) Asp-His). Turk J Hematol 2008, 25(1):48-50.

7. Rahimi Z, Akramipour R, Vaisi-Raygani A, Nagel RL, Muniz A: An Iranian child with HbQ-Iran [alpha75 (EF4) Asp->His]/-alpha3.7 kb/IVSII.1 G->A: first report. J Pediatr Hematol Oncol 2007, 29(9):649-651. 
8. Salehi R, Fisher CA, Bignell PA, Eslami G, Old JM: Identification of three novel mutations [-41 (A >C), codon $24(-\mathrm{G})$, and IVS-I-109 $(-\mathrm{T})]$, in a study of beta-thalassemia alleles in the Isfahan region of Iran. Hemoglobin 2010, 34(1):115-120.

9. Tamaddoni A, Hadavi V, Nejad NH, Khosh-Ain A, Siami R, Aghai-Meibodi J, Almadani N, Oberkanins C, Law HY, Najmabadi H: Alpha-Thalassemia mutation analyses in Mazandaran province, North Iran. Hemoglobin 2009, 33(2):115-123.

10. Mahdavi MR, Karimi M, Yavarian M, Roshan P, Kosaryan M, Siami R: Detection of $\mathrm{Hb}$ Setif in north Iran and the question of its origin: Iranian or multiethnic? Hemoglobin 2011, 35(2):152-156.

11. Dinçol G, Aksoy M, Dinçol K, Kutlar A, Wilson JB, Huisman TH: Hemoglobin hamadan or alpha 2 beta 256 (D7) Gly_-Arg in a Turkish family. Hemoglobin 1984, 8(4):423-425.

doi:10.1186/1752-1947-6-47

Cite this article as: Khorshidi et al: Hemoglobin Q-Iran detected in family members from Northern Iran: a case report. Journal of Medical Case Reports 2012 6:47.

\section{Submit your next manuscript to BioMed Central} and take full advantage of:

- Convenient online submission

- Thorough peer review

- No space constraints or color figure charges

- Immediate publication on acceptance

- Inclusion in PubMed, CAS, Scopus and Google Scholar

- Research which is freely available for redistribution

Submit your manuscript at www.biomedcentral.com/submit 